\title{
ERRATUM:
}

\section{Tobacco smoking, related harm and motivation to quit smoking in people with schizophrenia spectrum disorders}

\section{Pasquale Caponnetto, ${ }^{1,2}$ Riccardo Polosa ${ }^{1}$}

${ }^{1}$ University of Catania, Italy; ${ }^{2}$ University of Stirling, UK

Due to an error, dr. Deborah Robson and dr. Linda Bauld were mistakenly included as authors in this article, published in 2020 in

Health Psychology Research. DOI: 10.4081/hpr.2019.9042 -

PMCID: PMC7267811 - PMID: 32510003).

The correct authorship appears above. 